\title{
THE SIXTY-FORTH ANNUAL MEETING OF THE JAPANESE SOCIETY OF GASTROENTEROLOGY
}

The 64th Annual Meeting of the Society will be held under the chairmanship of Prof. Takeo Wada, M.D., Department of Internal Medicine, Sapporo Medical College, at the Hokkaido Kosei Nenkin Kaikan Hall, Sapporo City, Hokkaido, May 22 to 24, 1978.

The scientific program is as follows:

\section{Special lectures:}

1. Invited lectures:

(1) The cell exchange and pathology of the mucosa in the gastrointestinal tract

Prof. Sekiya Fujita, Department of Pathology, Kyoto Prefectural University of Medicine, Kyoto

(2) Carcinoembryonic antigens (CEA)

Prof. Hidematsu Hirai, Department of Biochemistry, Hokkaido University, Sapporo

(3) World-Wide Incidence of gastrointestinal cancer

Prof. Marvin Pollard, Department of Internal Medicine, University Hospital, Ann Arbor, Michigan, U.S.A.

\section{Chairman's lecture:}

Taking a general view of gastroenterology in 1978

\section{Symposia :}

Prof. Takeo Wada, Department of Internal Medicine, Sapporo Medical College, Sapporo

1. Biochemical and immunological approach to gastrointestinal cancer (Designated)

Co-Moderators: Dr. Ichiro Urushizaki, Sapporo Medical College

Dr. Goro Kozaki, Osaka University

2. Problems of viral hepatitis (Designated)

Co-Moderators: Dr. Hiroshi Suzuki, University of Tokyo

Dr. Hiroshi Sasaki, Niigata University

3. Recent trends of the research on gastrointestinal hormones (Invited)

Co-Moderators: Dr. Yutaka Matsuo, University of Tokyo

Dr. Akira Ishimori, Tohoku University

4. Hepato-pancreatic diseases viewed from hemato-biochemistry (Invited)

Co-Moderators: Dr. Kaneo Ishii, Asahikawa Medical College

III. Workshops:

Dr. Kiyoshi Fujisawa, Jikei University

1. Digestive organs and immunity:

(1) Immunology and pathology of the gastriointestinal tract

Co-Moderators: Dr. Shiro Hosoda, Shiga Medical University

Dr. Akira Yachi, Sapporo Medical College

(2) On hepato-pancreatic diseases:

Co-Moderators: Dr. Sukeo Yamamoto, Osaka City University

Dr. Tatsuji Homma, Shinshu University

2. Lower esophageal disorders:

(1) Clinic of LES

(2) Treatment of esophageal varix

3. Pathology and treatment of gastro-duodenal ulcer

4. Advanced diagnosis and treatment of hepato-pancreatic tumor

5. Studies on the hormones of the gastrointestinal tract

\section{Freeap pers.}

Further information may be obtained from the Secretariat of Japanese Society of Gastroenterology, c/o Gyosei Bldg., 4-12 Ginza 7-chome, Chuo-ku, Tokyo, 104 Japan. 